\title{
Article \\ Experimental Study on Diesel Engine Emission Characteristics Based on Different Exhaust Pipe Coating Schemes
}

\author{
Keqin Zhao (D), Diming Lou, Yunhua Zhang *, Liang Fang (D) and Yuanzhi Tang \\ School of Automobiles Studies, Tongji University, Shanghai 201804, China; zhaokeqin@tongji.edu.cn (K.Z.); \\ loudiming@tongji.edu.cn (D.L.); fangliang@tongii.edu.cn (L.F.); tangyuanzhi@tongji.edu.cn (Y.T.) \\ * Correspondence: zhangyunhua131@tongji.edu.cn
}

Citation: Zhao, K.; Lou, D.; Zhang, Y.; Fang, L.; Tang, Y. Experimental Study on Diesel Engine Emission Characteristics Based on Different Exhaust Pipe Coating Schemes. Micromachines 2021, 12, 1155. https://doi.org/10.3390/ mi12101155

Academic Editor: Kun Li

Received: 2 September 2021

Accepted: 24 September 2021

Published: 25 September 2021

Publisher's Note: MDPI stays neutral with regard to jurisdictional claims in published maps and institutional affiliations.

Copyright: (c) 2021 by the authors. Licensee MDPI, Basel, Switzerland. This article is an open access article distributed under the terms and conditions of the Creative Commons Attribution (CC BY) license (https:// creativecommons.org/licenses/by/ $4.0 /)$.
Abstract: The thermal insulation performance of exhaust pipes coated with various materials (basalt and glass fiber materials) under different braiding forms (sleeve, winding and felt types) and the effects on the emission characteristics of diesel engines were experimentally studied through engine bench tests. The results indicated that the thermal insulation performance of basalt fiber was higher than that of glass fiber, and more notably advantageous at the early stage of the diesel engine idle cold phase. The average temperature drop during the first $600 \mathrm{~s}$ of the basalt felt (BF) pipe was $2.6^{\circ} \mathrm{C}$ smaller than that of the glass fiber felt (GF) pipe. Comparing the different braiding forms, the temperature decrease in the felt-type braided material was $2.6^{\circ} \mathrm{C}$ and $2.9^{\circ} \mathrm{C}$ smaller than that in the sleeve- and winding-type braided materials, respectively. The basalt material was better than the glass fiber material regarding the gaseous pollutant emission reduction performance, especially in the idling cold phase of diesel engines. The $\mathrm{NO}_{\mathrm{x}}$ conversion rate of the $\mathrm{BF}$ pipe was $7.4 \%$ higher than that of the GF pipe, and the hydrocarbon (HC) conversion rate was $2.3 \%$ higher than that of the GF pipe, while the CO conversion rate during the first $100 \mathrm{~s}$ was $24.5 \%$ higher than that of the GF pipe. However, the particulate matter emissions were not notably different.

Keywords: diesel engine bench test; basalt fiber; glass fiber; thermal insulation performance; emission characteristics

\section{Introduction}

Diesel engines are widely applied in the field of commercial vehicles due to their good power features, fuel economy, and reliability. Although they have many advantages, they have a significant impact on the problem of environmental pollution worldwide [1,2]. The nitrogen oxide $\left(\mathrm{NO}_{\mathrm{x}}\right)$ and particulate matter emissions of diesel engines are considerable, accounting for $70 \%$ and $90 \%$, respectively, of the total vehicle emissions, and are also responsible for several health problems [3,4]. To limit the pollutant emissions originating from diesel vehicles, various countries have continuously tightened emission limits, broadened the requirements for low-temperature and low-load emission pollutant control, and greatly reduced the $\mathrm{NO}_{x}$ emission concentration limit. The combination of various after-treatment technologies has become an important means to improve vehicle pollutant emissions and meet the increasingly stringent emission regulations. At present, aftertreatment devices largely include optimized combustion + selective catalytic reduction $(\mathrm{SCR})$, and exhaust gas recirculation (EGR) + diesel oxidation catalyst (DOC) + diesel particulate filter (DPF) [5-8]. The exhaust temperature is the main factor influencing the purification effect of the exhaust gas thermal reaction and the after-treatment performance. Within a certain temperature range, the higher the exhaust temperature, the better the purification effect of the thermal reaction [9]. If the exhaust temperature is too low, this may cause problems such as urea solution crystallization in the SCR device [10,11]. Therefore, to improve the catalytic efficiency of after-treatment devices, it is necessary to coat exhaust pipes with an insulating material to reduce heat loss, thereby improving the emission performance of the entire vehicle. 
At present, glass fiber and asbestos fiber are mainly used as the insulation materials in the exhaust pipe, but long-term exposure to glass fiber and asbestos fiber will damage the respiratory system and cause health hazards $[12,13]$. Therefore, it is very important to study new alternative materials. Basalt fiber has increasingly become a substitute for glass fiber in many fields, such as marine and military industries, due to its excellent performance. Additionally, BF is labeled as safe, according to both the USA and the European occupational safety guidelines.

Basalt fiber is a new natural green material. It consists of volcanic extruded rock. Its chemical composition is similar to that of gabbro. $\mathrm{The}^{\mathrm{SiO}}{ }_{2}$ content varies between $45 \%$ and $60 \%$. The $\mathrm{K}_{2} \mathrm{O}+\mathrm{Na}_{2} \mathrm{O}$ content is slightly higher than that in intrusive rocks. The $\mathrm{Fe}_{2} \mathrm{O}_{3}+\mathrm{FeO}$ and $\mathrm{MgO}$ contents are slightly lower than those in intrusive rocks. Fiber is produced by putting material into a furnace where it is melted at $1450-1500{ }^{\circ} \mathrm{C}$. Subsequently, the molten material is forced through a platinum/rhodium crucible bushing to create fibers. Compared with glass fiber, basalt fiber is cheaper to produce due to less energy consumed and no additives being required. Additionally, it attains a better hightemperature resistance than glass fiber. Basalt fiber achieves a wider temperature range, from -200 to $800{ }^{\circ} \mathrm{C}$, while the temperature range attained by glass fiber varies between approximately $-60^{\circ} \mathrm{C}$ and $450{ }^{\circ} \mathrm{C}$ [14]. At a working temperature of $400^{\circ} \mathrm{C}$, the breaking strength of basalt fiber can be maintained at $85 \%$, while at a working temperature of $600{ }^{\circ} \mathrm{C}$, its breaking strength can still be maintained at $80 \%$. Moreover, if basalt fiber is pretreated at a temperature ranging from 780 to $820^{\circ} \mathrm{C}$, it can be applied at $860^{\circ} \mathrm{C}$ without shrinkage [15]. Due to its excellent high-temperature resistance, basalt fiber has been widely adopted in transportation infrastructure, environmental protection and other fields [16-21].

In recent years, scholars have conducted research on the thermal properties of basalt and glass fiber materials. Their research results indicated that basalt fiber contained a large number of micropores to prevent air convection and heat radiation, and its thermal insulation performance was higher than that of glass fiber [22]; under exposure to the same radiant heat flux, basalt fiber material reached a higher temperature faster than glass fiber material due to its higher thermal emissivity [23]; mass loss occurred in the temperature range of 200 to $350^{\circ} \mathrm{C}$, the thermal decomposition temperature of basalt fiber was $40{ }^{\circ} \mathrm{C}$ higher than that of glass fiber, and basalt fiber reached a higher thermal stability [24]. Therefore, basalt fiber provides certain advantages over glass fiber in terms of its thermal performance, and as it is widely used in car mufflers and other parts in the automotive industry [25], basalt fiber exhibits a certain potential in diesel engine thermal management applications. However, there are still few studies on its application in the after-treatment thermal management of diesel engines.

This paper relies on diesel engine bench tests to assess the thermal insulation performance of different exhaust pipe covering schemes considering basalt and glass fiber materials. Moreover, various basalt fiber weaving forms (basalt sleeve (BS), basalt winding $(\mathrm{BW})$, and basalt felt (BF)) and their influence on the emission characteristics of diesel engines are investigated herein.

\section{Methodology}

\subsection{Test Materials}

The test exhaust pipe samples adopted basalt sleeve (BS), basalt winding (BW), basalt felt (BF), and glass fiber felt (GF) with the equal thickness and bulk density. The variety of covering samples is presented in Table 1. 
Table 1. Test sample.

\begin{tabular}{|c|c|c|c|c|c|c|}
\hline $\begin{array}{c}\text { Serial } \\
\text { Number }\end{array}$ & Prototype & $\begin{array}{l}\text { Thickness } \\
\text { (mm) }\end{array}$ & $\begin{array}{l}\text { Bulk Density } \\
\quad\left(\mathrm{kg} \cdot \mathrm{m}^{-3}\right)\end{array}$ & $\begin{array}{c}\text { Thermal } \\
\text { Conductivity } \\
(\mathrm{W} / \mathrm{m} \cdot \mathrm{k})\end{array}$ & $\begin{array}{c}\text { End-Use } \\
\text { Temperature } \\
\left({ }^{\circ} \mathrm{C}\right)\end{array}$ & Morphology \\
\hline 1 & BS & 5 & 120 & 0.031 & 780 & \\
\hline 2 & BW & 5 & 120 & 0.031 & 780 & $\bullet$ \\
\hline 3 & $\mathrm{BF}$ & 5 & 120 & 0.031 & 780 & \\
\hline 4 & GF & 5 & 120 & 0.049 & 400 & \\
\hline
\end{tabular}

\subsection{Test Device and Data Processing}

The test device mainly included a diesel engine for the test and the bench test system. The system consisted of a Horiba 7200D and an AVL489. The Horiba 7200D was used to measure the $\mathrm{CO}, \mathrm{THC}, \mathrm{NOx}$, etc., and the AVL489 was used to measure the particle emissions. Table 2 lists the technical parameters of the diesel engine type adopted in the test, and Table 3 summarizes the composition and model of the sampling equipment of the diesel engine bench test system.

Table 2. Parameters of the diesel engine.

\begin{tabular}{cc}
\hline Project & Parameter \\
\hline Diesel engine model & D45 \\
Displacement/L & 4.5 \\
Rated power $/ \mathrm{kW}$ & 150 \\
Rated speed $/ \mathrm{r}$ min $^{-1}$ & 2300 \\
After-treatment device & DOC + SCR + DPF \\
\hline
\end{tabular}

Table 3. Sampling equipment and models.

\begin{tabular}{ccc}
\hline Sample Item & Device Model & Sample Content \\
\hline Gaseous substance & Horiba 7200D & NOx, CO, and hydrocarbons (HCs) \\
Number of particles (PN) & AVL489 & PN \\
\hline
\end{tabular}

Through the bench test, the original emission data of different pollutants before entering the after-treatment system, and the emission data of different pollutants through the after-treatment system with different covering schemes, was obtained. Finally, the conversion rate of different pollutants was determined, and the calculation method is shown in Equation (1) where PE1 is the original emission data, PE2 is the emission data after, and CR is the conversion rate of different pollutants.

$$
\mathrm{CR}=\frac{\mathrm{PE} 1-\mathrm{PE} 2}{\mathrm{PE} 1} \times 100 \%
$$

\subsection{Test Conditions and Plan}

The cold test of the diesel engine bench adopted the World Harmonized Transient Cycle (WHTC) heavy-duty diesel engine test cycle. The WHTC cycle is a transient operating condition lasting $1800 \mathrm{~s}$ that changes at $1 \mathrm{~s}$ intervals. The cycle is divided into three stages, namely, 0 600 s as the cold operation stage, 600 1200 s as the transition stage, and $1200 \sim 1800 \mathrm{~s}$ as the hot operation stage, as shown in Figure 1. 


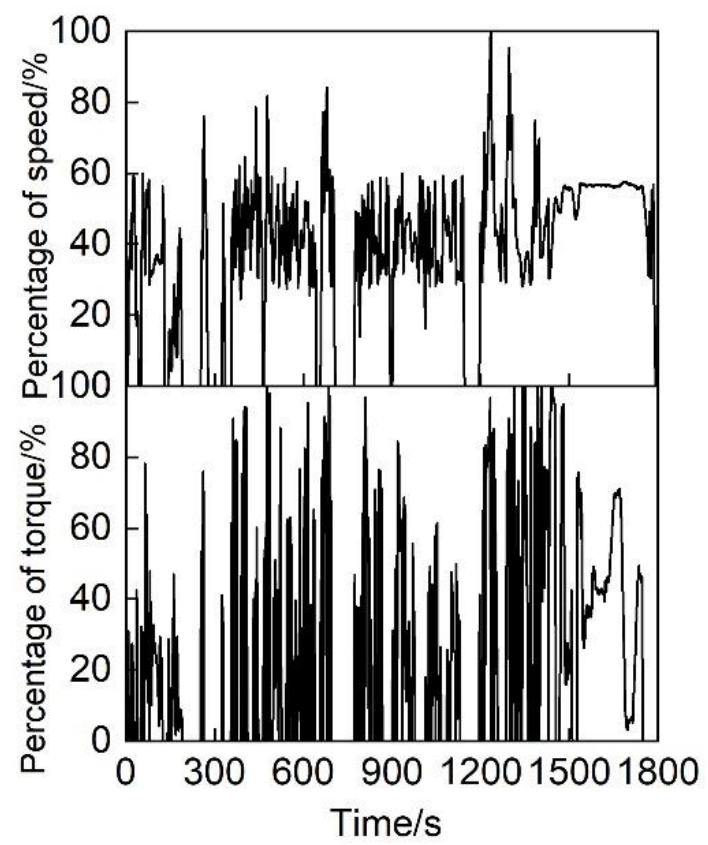

Figure 1. Schematic diagram of the WHTC cycle.

The exhaust pipes were coated with basalt and glass fiber materials with equal thickness and bulk density. The glass fiber material adopted the felt-type weaving method. The basalt fiber material was subjected to three different weaving methods, i.e., sleeve, winding and felt types. The temperature at the outlet end of the diesel engine, and at the inlet of the after-treatment system, was measured under cycling conditions. The heat preservation characteristics of the entire exhaust system were studied, and the emission characteristics $\left(\mathrm{NO}_{\mathrm{x}}, \mathrm{CO}, \mathrm{HC}\right.$, and $\left.\mathrm{PN}\right)$ of the diesel engine containing an exhaust system coated with the above two materials under the same cycle, were analyzed. The test plan is listed in Table 4, and the layout of the test bench and temperature measurement points are shown in Figure 2.

Table 4. Test plan.

\begin{tabular}{ccc}
\hline Exhaust Gas Temperature & Emission Data & Test Cycle \\
\hline 1. T1 before the pipe & Gaseous substances: CO, HCs, and NOx & WHTC (cold state) \\
2. T2 after the pipe & Number of particles: PN & \\
\hline
\end{tabular}

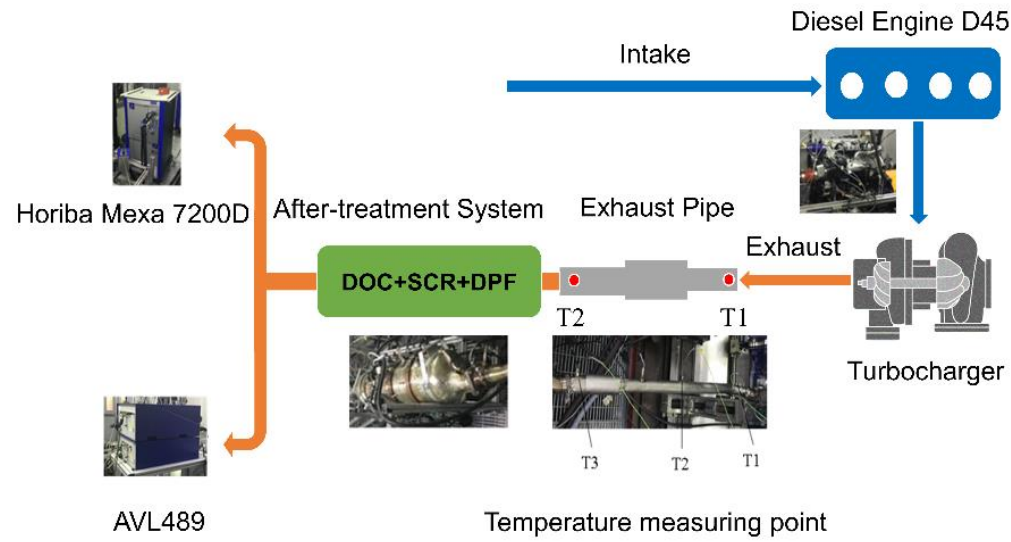

Figure 2. Layout of the test bench and temperature measurement points. 


\section{Results and Discussion}

\subsection{Exhaust Temperature Analysis of the Full Cycle}

Figure 3 shows the exhaust gas temperature $\mathrm{T} 1$ at the rear end of the vortex over time for the different exhaust pipe covering schemes of the tested diesel engine. In essence, the temperature measured at the T1 measurement point of the exhaust pipes with the different materials and covering methods was basically the same, because it was the outlet temperature of the turbocharger and was less affected by the insulation material. The average temperature at each stage during cold, transition and hot operation exhibited a stepwise upward trend, at $201{ }^{\circ} \mathrm{C}, 258^{\circ} \mathrm{C}$ and $328^{\circ} \mathrm{C}$, respectively.

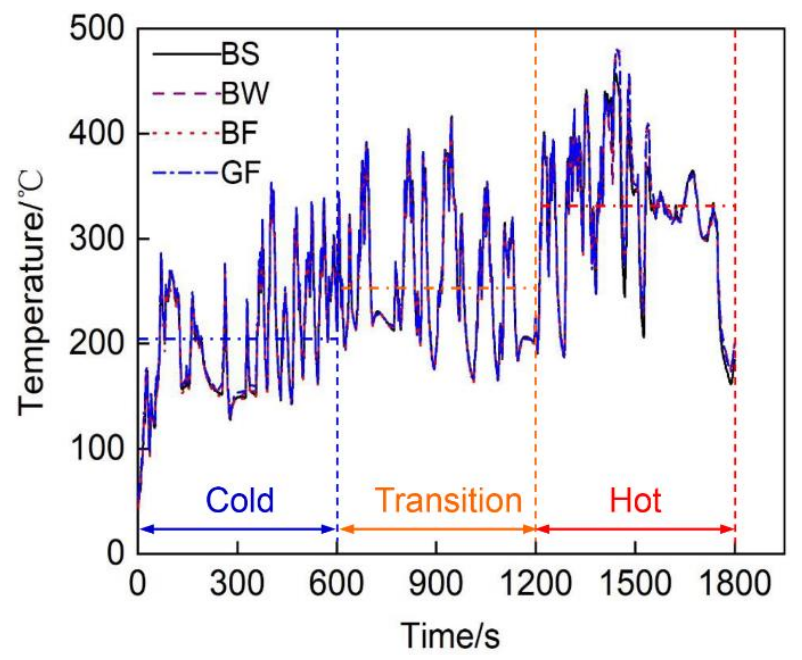

Figure 3. Temperature at the T1 measurement point of the exhaust pipes with different covering schemes over time.

$\mathrm{T} 2$ is the temperature at the inlet of the after-treatment system, and its specific changes throughout the cycle are shown in Figure 4. At the T2 measurement point, the exhaust temperature of the exhaust pipes with the different materials and covering methods greatly varied (especially in the cold cycle). The exhaust temperatures of the BS and BW pipes at the cold operation stage were lower than those of the other pipes. Their average temperatures were $3{ }^{\circ} \mathrm{C}$ and $2{ }^{\circ} \mathrm{C}$, respectively, lower than the overall average temperature in the cold phase.

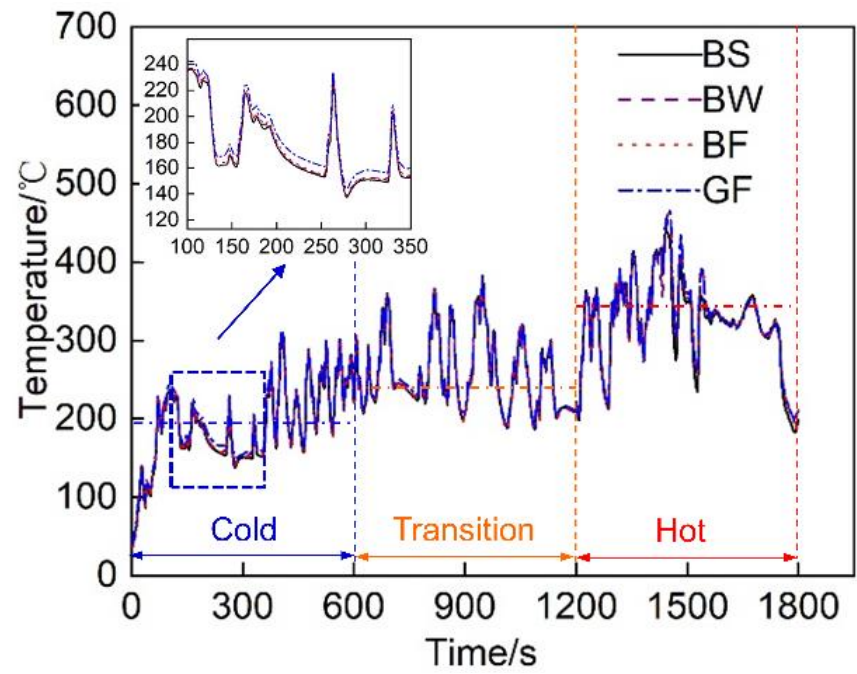

Figure 4. Temperature at the $\mathrm{T} 2$ measurement point of the exhaust pipes with different covering schemes over time. 
This test considered T1-T2 $(\Delta \mathrm{T})$ to intuitively simulate the thermal insulation performance of the vehicle exhaust pipe system. Figure 5 shows the evolution of the temperature decrease in the exhaust pipes with different covering schemes. The overall exhaust pipe temperature experienced a downward trend. This mainly occurred because the exhaust pipe operated in the cold state upon cold start initiation. Some of the heat flux preheated the exhaust pipe, resulting in a notable heat energy loss, therefore the temperature decline was large. With increasing exhaust pipe temperature, the heat loss attributed to preheating gradually decreased, reducing the temperature drop. Figure 6 shows the average temperature drop considering the different covering schemes for the entire circulating exhaust pipe. The results indicated that the average temperature decrease in the BF pipe during the entire cycle was the smallest, which was $0.5^{\circ} \mathrm{C}$ smaller than that in the GF pipe. This occurred because basalt fiber is composed of tectosilicates, phyllosilicates, chain silicates, and orthosilicates [26]. The amorphous region in the interior was large, and many grain boundaries, defects and impurities existed. This resulted in a low thermal conductivity. Therefore, the thermal insulation performance of the basalt fiber material was better than that of the glass fiber material. Comparing the different basalt material weaving methods, the average temperature decrease in the exhaust pipe coated with BF was $2.6{ }^{\circ} \mathrm{C}$ and $2.9^{\circ} \mathrm{C}$ smaller than that in the exhaust pipes coated with BS and BW, respectively, and the heat preservation performance was higher than that of the other two weaving forms. This occurred due to the large size of the pores of the sleeve- and winding-type materials, resulting in serious heat loss and a poor thermal insulation performance.

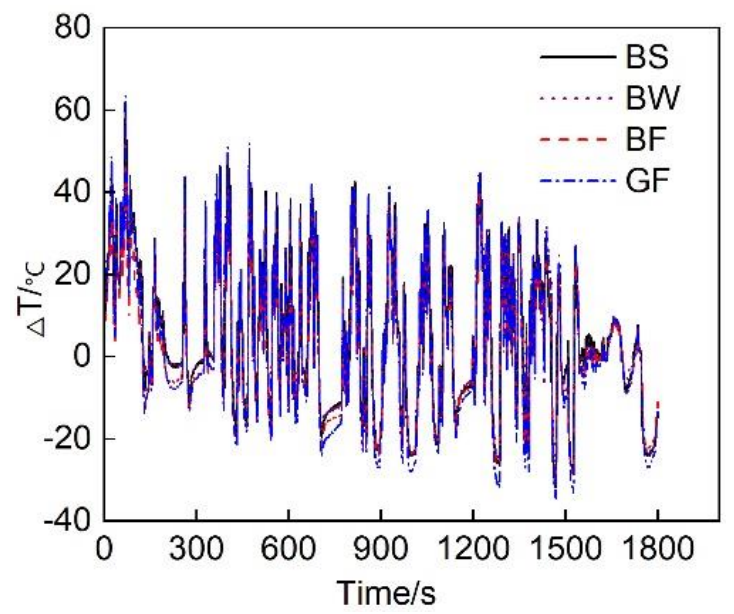

Figure 5. Temperature decrease $\Delta \mathrm{T}$ in the exhaust pipes with different covering schemes over time.

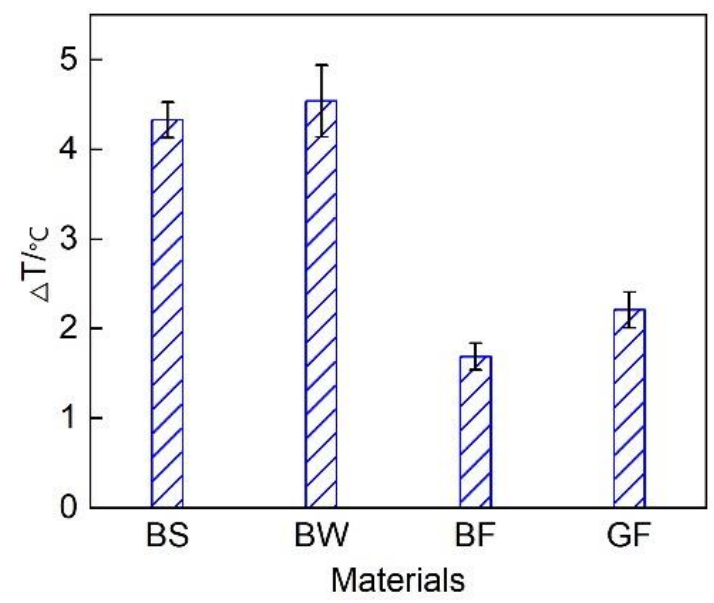

Figure 6. Average temperature decrease in the exhaust pipes with different covering schemes. 


\subsection{Emission Analysis of the Full Cycle}

Figure 7 shows a comparison of the $\mathrm{NO}_{\mathrm{x}}$ conversion efficiency of the exhaust pipes between the different covering schemes during each cycle of the diesel engine. The figure reveals that with an increasing load, the $\mathrm{NO}_{\mathrm{x}}$ conversion rate gradually increased. Figure 4 shows that the exhaust gas temperature rose, thus promoting SCR. During the first $600 \mathrm{~s}$ of the cold-state operation stage, the SCR inlet temperature was low, and the $\mathrm{NO}_{\mathrm{x}}$ conversion rate of each pipe did not exceed 50\% [27]. At the transition stage (600 1200 s) and hotstate operation stage (1200 1800 s), the $\mathrm{NO}_{\mathrm{x}}$ conversion rate of each pipe was greatly improved; this occurred because DOC in the range of $200 \sim 400{ }^{\circ} \mathrm{C}$ can effectively improve the $\mathrm{NO}_{2} / \mathrm{NO}_{\mathrm{x}}$ ratio and improve the $\mathrm{NO}_{\mathrm{x}}$ conversion rate [28]. Regardless of the operation stage, the average $\mathrm{NO}_{x}$ conversion rate of the $\mathrm{BF}$ pipe was the highest. At the cold operation stage, the average $\mathrm{NO}_{\mathrm{x}}$ conversion rate of the $\mathrm{BF}$ pipe was $47.6 \%, 97.6 \%$ and $7.4 \%$ higher than that of the BS, BW and GF pipes, respectively. At the transition stage (600 1200 s) and hot operation stage (1200 1800 s), the average $\mathrm{NO}_{x}$ conversion rate was $13.6 \%, 3 \%$ and $11 \%$ higher, respectively, than that of the other three pipes.

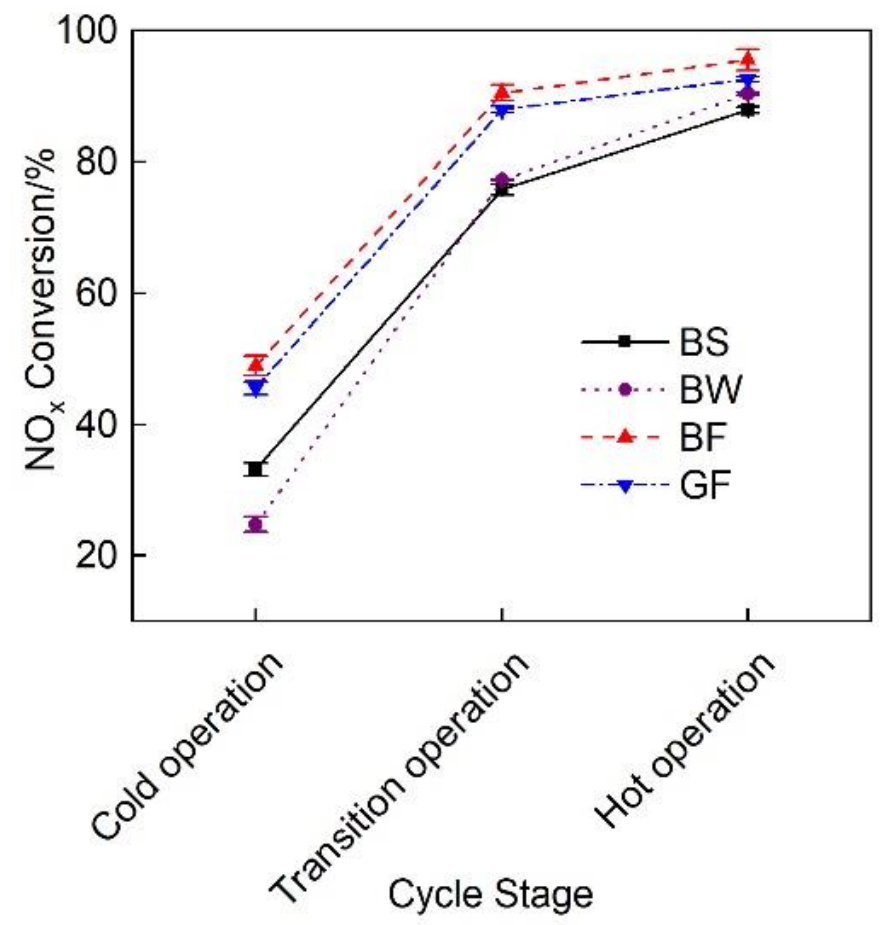

Figure 7. $\mathrm{NO}_{\mathrm{x}}$ conversion rate of the different exhaust pipe covering schemes.

Figure 8 shows the average $\mathrm{CO}$ conversion rate of the exhaust pipes with the different covering schemes during the WHTC cycle. Under the emission reduction effect of the DOC and DPF device combination, the CO conversion rate of each pipe was maintained at a high level [29], reaching above $85 \%$, and with the increase in exhaust temperature, CO oxidation was promoted and $\mathrm{CO}$ conversion rate increased [30]. The average $\mathrm{CO}$ conversion rate of the BF pipe was $1.1 \%, 2.7 \%$ and $4.3 \%$ higher than that of the BS, BW and GF pipes, respectively, but these differences were small.

Figure 9 shows the HC conversion efficiency of the exhaust pipes with the different covering schemes at each cycle stage. The figure revealed that the overall $\mathrm{HC}$ conversion efficiency gradually increased. The average HC conversion rate of the BF pipe reached $96.7 \%$, which was $6.9 \%, 8.3 \%$ and $1.3 \%$ higher than that of the BS, BW and GF pipes, respectively. 


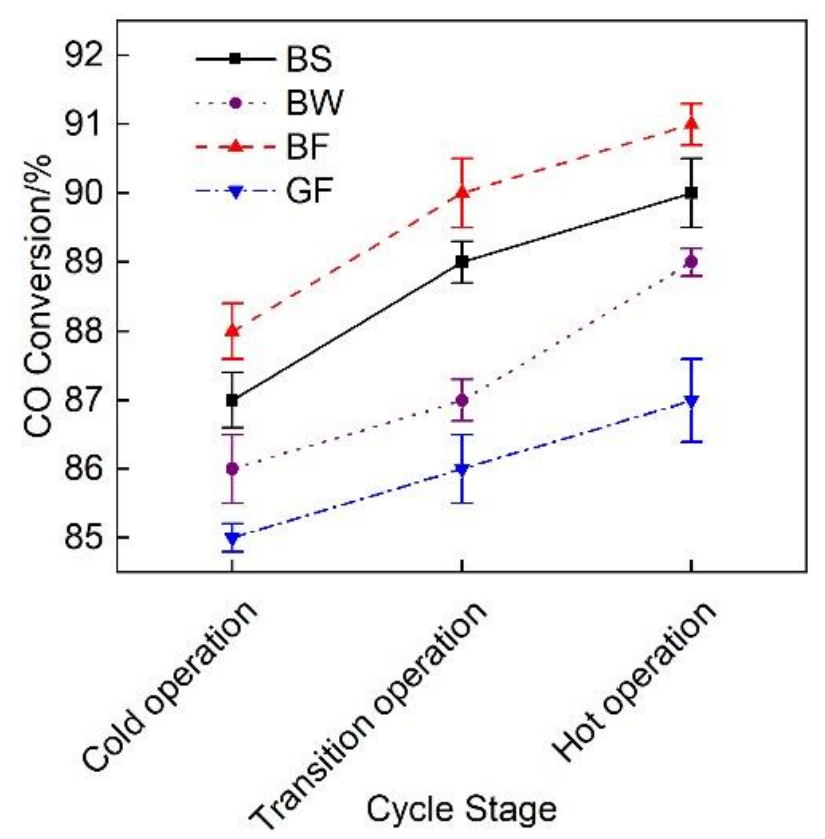

Figure 8. CO conversion rate of the different exhaust pipe covering schemes.

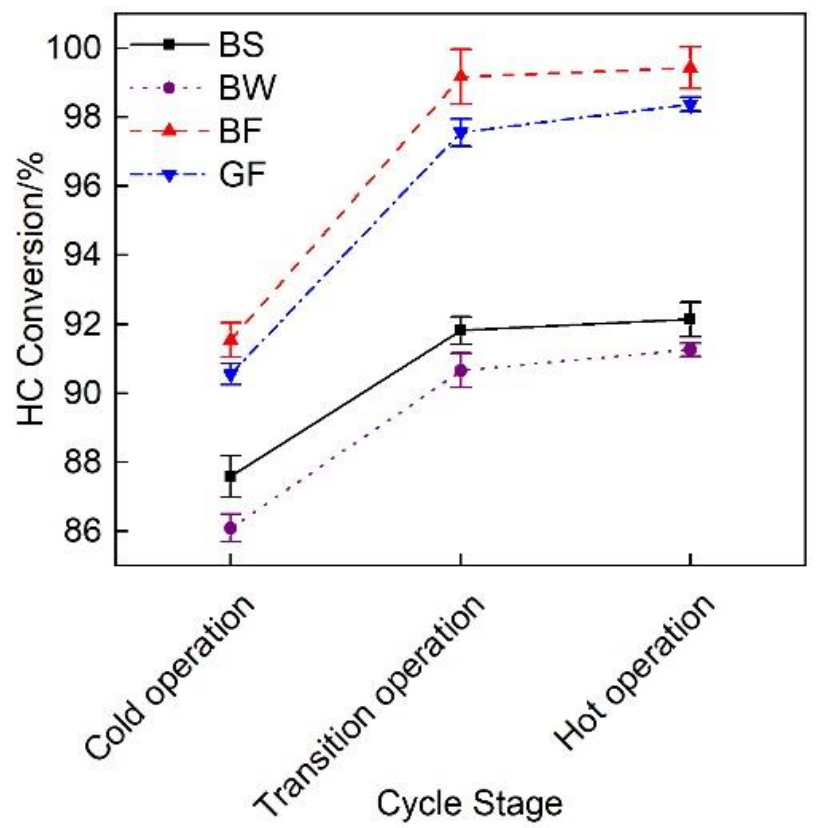

Figure 9. HC conversion rate of the different exhaust pipe covering schemes.

Figure 10 shows the change curve of the particulate matter concentration of the exhaust pipes with the different covering schemes at each cycle stage. Under the effects of the DOC and DPF device combination, the particulate matter emissions of the different insulated pipes were relatively low and exhibited a trend of decreasing first and then slightly increasing. This occurred because at the beginning of the cycle, the exhaust temperature was low and the DOC performance was not high. During hot-state operation, a high exhaust temperature promoted the production of sulfate [31], thus causing a slight increase in particulate matter emissions. 


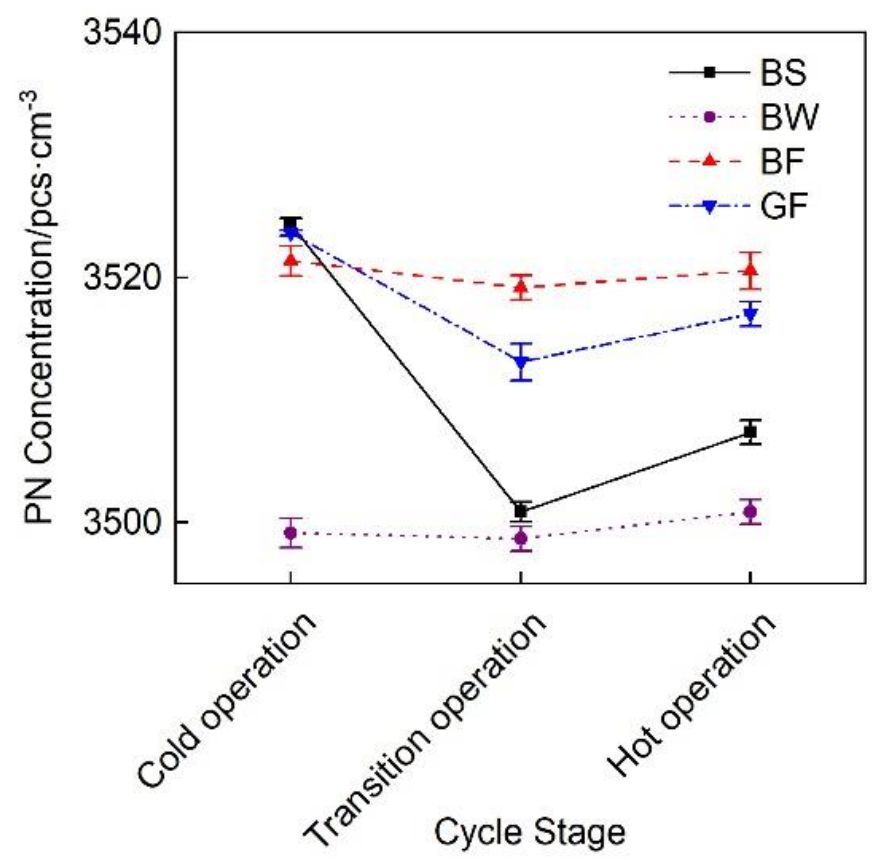

Figure 10. PN concentration change considering the different exhaust pipe covering schemes.

Figure 11 shows the total emissions of gaseous pollutants and particulates during the WHTC cycle of the exhaust pipes with different covering schemes. It is observed that little difference existed in particulate matter emissions. Due to its better thermal insulation performance, the BF pipe achieved a high after-treatment system conversion efficiency, and the gaseous pollutant emissions were the lowest. The total emissions were $67.3 \%, 49.8 \%$ and $23.2 \%$ lower than those of the BS, BW and GF pipes, respectively.

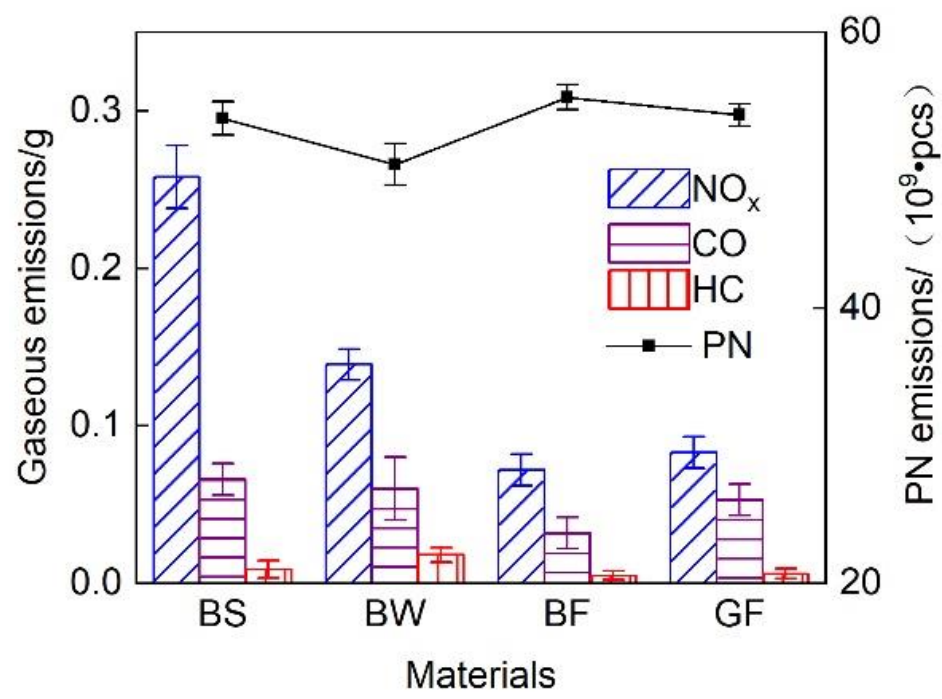

Figure 11. Total emissions during the WHTC cycle.

\subsection{Exhaust Temperature Analysis during Cold Operation}

Since the WHTC cycle focuses more on the investigation of diesel engine emissions under low-speed and low-load conditions, the diesel engine emission temperature during this cycle is low, and the performance requirements of the SCR after-treatment system are high. Therefore, it is very important to study the temperature and corresponding emission characteristics of cold-state operation. Based on the test results, the cold operation stage (0-600 s) was subdivided, and the change law of the average temperature drop at each substage of the initial cold operation stage was further analyzed. 
Figure 12 shows the average temperature drop of the exhaust pipes with the different covering schemes at the various substages of the initial cold-state operation stage. During the cold operation cycle of the diesel engine, the average temperature decrease in the $\mathrm{BF}$ pipe over the first $600 \mathrm{~s}$ was $2.6^{\circ} \mathrm{C}$ smaller than that in the GF pipe.

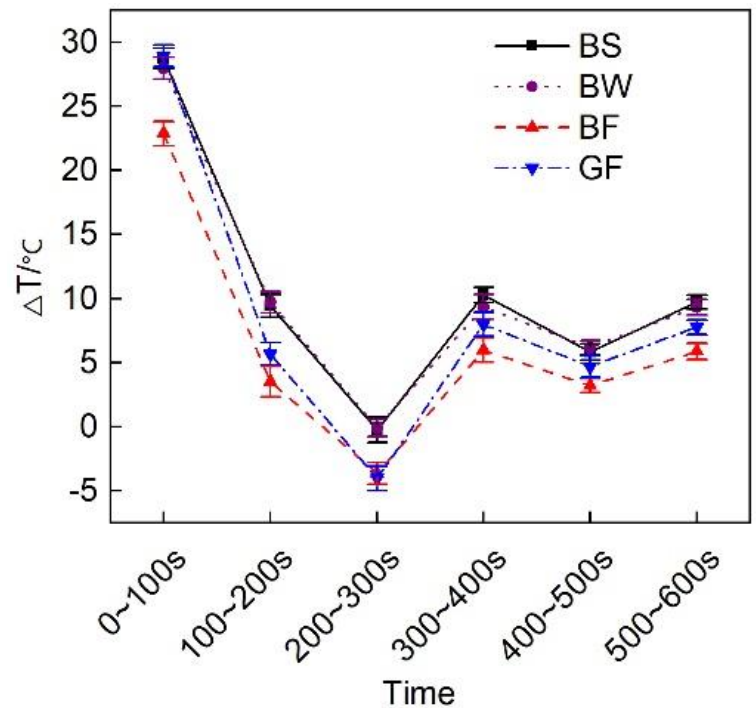

Figure 12. Average temperature drop at each substage of the initial idling stage.

\subsection{Analysis of the Emission Results during Cold Operation}

Figure 13 shows a comparison of the $\mathrm{NO}_{\mathrm{x}}$ conversion efficiency of the exhaust pipes between the different covering schemes at each stage of cold operation. It is observed that the $\mathrm{NO}_{\mathrm{x}}$ conversion rate during the first $100 \mathrm{~s}$ was lower than $20 \%$. This finding matches the temperature characteristics. Figure 4 shows that during the first $100 \mathrm{~s}$, the average exhaust gas temperature entering the after-treatment system was lower than $200{ }^{\circ} \mathrm{C}$, resulting in a low SCR catalytic activity and a low $\mathrm{NO}_{x}$ conversion rate. The discharge performance of the BF pipe was the highest during cold-state operation, and the average $\mathrm{NO}_{x}$ conversion efficiency was $47.6 \%, 97.6 \%$, and $7.4 \%$ higher than that of the $\mathrm{BS}$, BW and GF pipes, respectively.

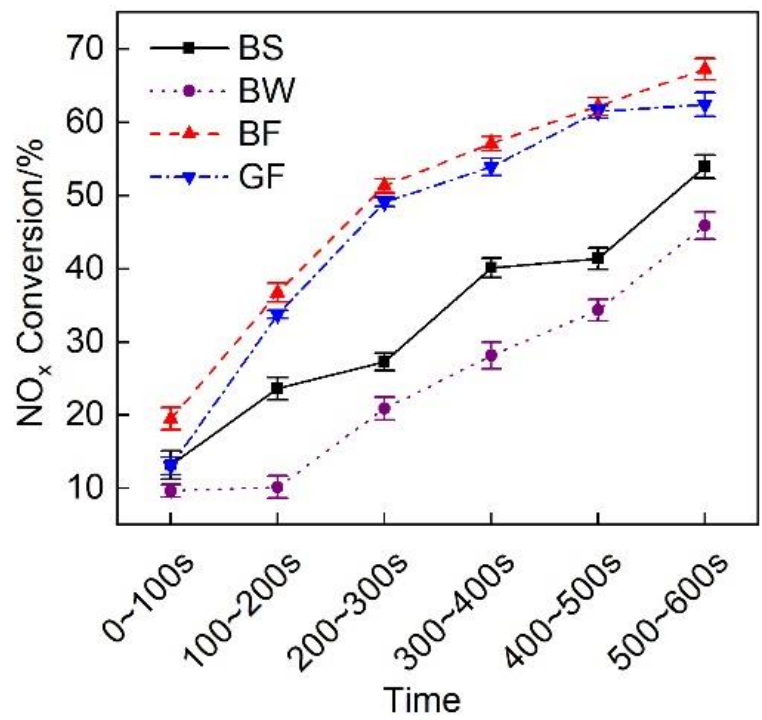

Figure 13. $\mathrm{NO}_{\mathrm{x}}$ conversion efficiency at each substage of the initial idling stage of the different exhaust pipe covering schemes. 
Figure 14 shows the $\mathrm{CO}$ conversion efficiency of the exhaust pipes with the different covering schemes at each stage during cold operation. Figure 14 shows that the $\mathrm{CO}$ conversion rate was low during the first $100 \mathrm{~s}$ and remained high during the next $500 \mathrm{~s}$. The discharge effect of the BF pipe during the first $100 \mathrm{~s}$ was obviously better than that of the GF pipe, and the $\mathrm{CO}$ conversion rate of the BF pipe was $24.5 \%$ higher than that of the GF pipe.

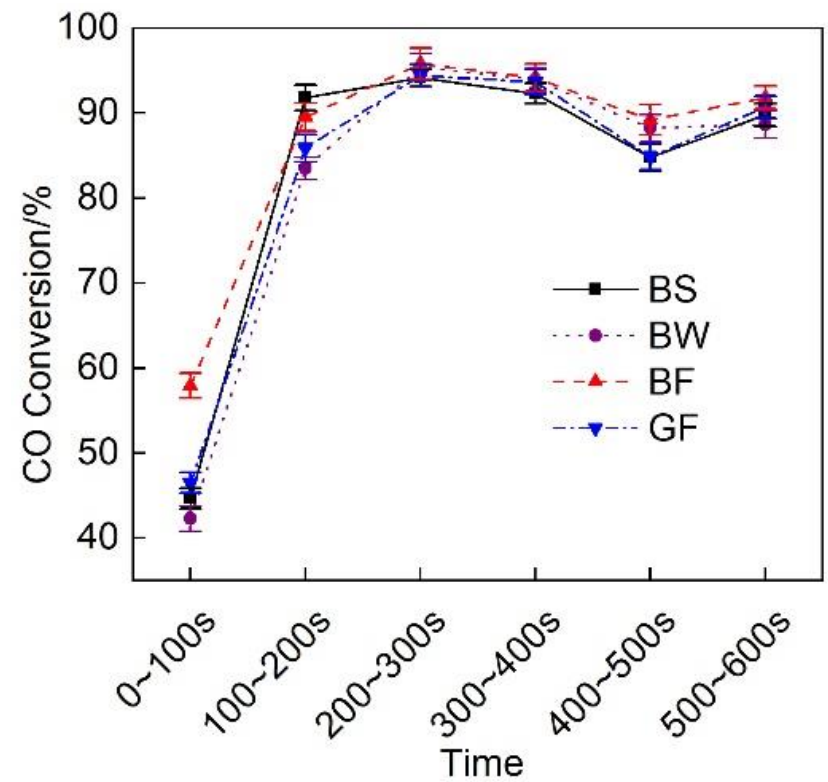

Figure 14. CO conversion efficiency at each substage of the initial idling stage of the different exhaust pipe covering schemes.

Figure 15 shows a comparison of the HC conversion efficiency of the exhaust pipes between the different covering schemes at each stage during cold operation. The figure revealed that the $\mathrm{HC}$ conversion rate at each stage was high, being not lower than $75 \%$. The HC conversion rate of the BF pipe was relatively high. The average HC conversion rate at the cold operation stage reached $92 \%$, which was $2.3 \%$ higher than that of the GF pipe.

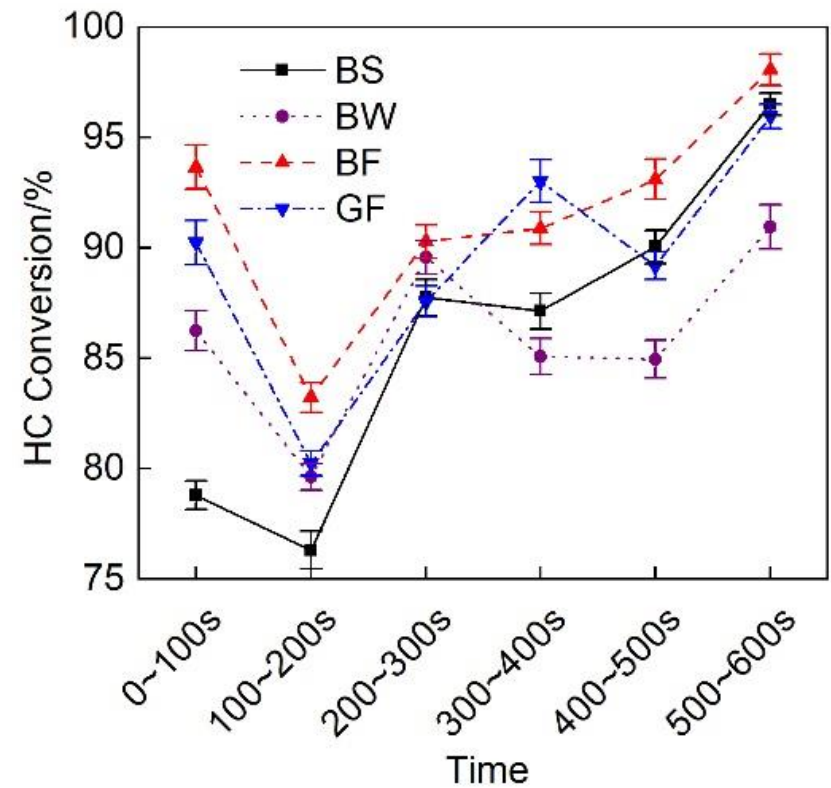

Figure 15. HC conversion efficiency of the different exhaust pipe covering schemes at each substage of the initial idling stage. 
Figure 16 shows a comparison of the particulate matter emissions of the exhaust pipes between the different covering schemes at each stage during cold operation. Figure 16 shows that the particulate matter emissions of the BF pipe were the lowest.

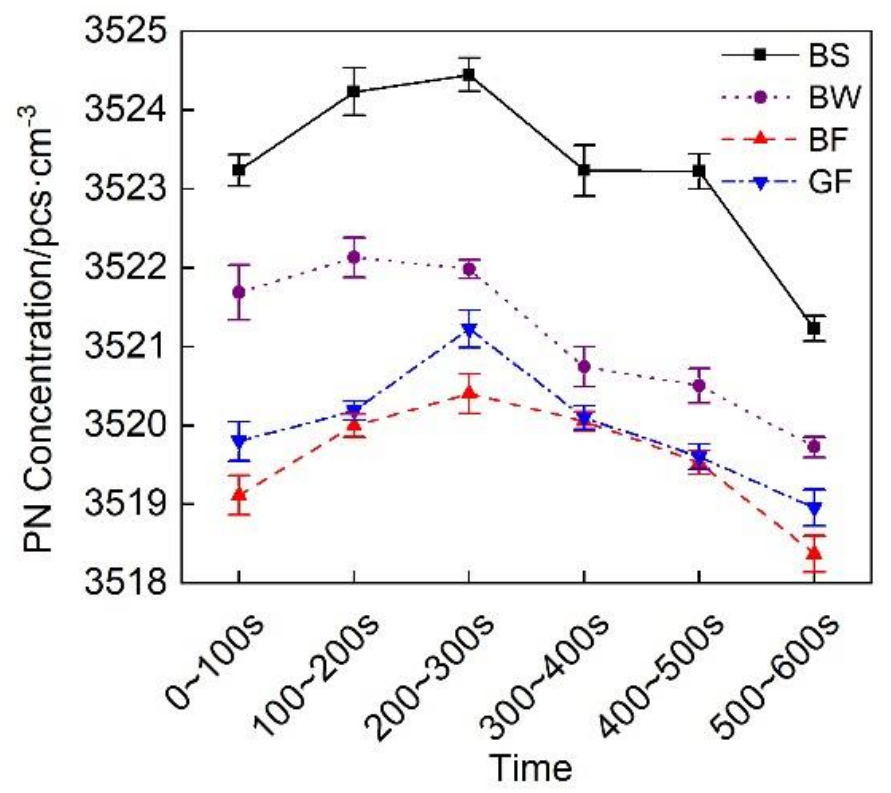

Figure 16. PN concentration of the different exhaust pipe covering schemes at each substage of the initial idling stage.

\section{Conclusions}

This paper presented an experimental study on the thermal insulation performance of exhaust pipes coated with various materials (basalt and glass fiber materials) under different braiding forms (sleeve, winding and felt types) and the effects on the emission characteristics of diesel engines. The following conclusions can be drawn from this study.

The thermal insulation performance of the basalt fiber material is better than that of the glass fiber material. This occurs because the thermal conductivity of the basalt fiber material is lower than that of the glass fiber material. The average temperature decrease in the BF pipe throughout the entire cold WHTC cycle is the smallest, and its average temperature is $0.5^{\circ} \mathrm{C}$ lower than that of the GF pipe, which is a small difference. During the $600 \mathrm{~s}$ period before the cold cycle, the thermal insulation performance of the basalt fiber material is obviously better than that of the glass fiber material, and the average temperature drop is $2.6^{\circ} \mathrm{C}$ smaller than that of the GF pipe. The basalt fiber material of the felt covering type attains the best thermal insulation performance, and the average temperature drop is $2.6^{\circ} \mathrm{C}$ and $2.9^{\circ} \mathrm{C}$ smaller than that of the sleeve- and winding-type materials, respectively.

The gaseous pollutant emission performance of the after-treatment system coated with basalt fiber material is better than that of the after-treatment system coated with glass fiber material. Throughout the full WHTC cycle, during the transition phase (600 1200 s) and the thermal operation phase (1200 1800 s), the average conversion rates of $\mathrm{NO}_{x}, \mathrm{CO}$ and $\mathrm{HCs}$ of each pipe are obviously improved. The average conversion rates of $\mathrm{NO}_{\mathrm{x}}, \mathrm{CO}$, and $\mathrm{HCs}$ of the $\mathrm{BF}$ pipe are all the highest. Among them, the average $\mathrm{NO}_{\mathrm{x}}$ conversion rate is $13.6 \%, 11 \%$ and $3 \%$ higher than that of the BS, BW and GF pipes, respectively. The BF pipe average $\mathrm{CO}$ conversion rate is $1.1 \%, 2.7 \%$, and $4.3 \%$ higher, respectively, and the $\mathrm{BF}$ pipe average $\mathrm{HC}$ conversion rate is $6.9 \%, 8.3 \%$, and $1.3 \%$ higher, respectively.

During the first $600 \mathrm{~s}$ of the cold operation stage, the gaseous pollutant emission performance of the basalt fiber-coated after-treatment system is notably higher than that of the glass fiber-coated after-treatment system. The NOx conversion rate of the BF pipe is $7.4 \%$ higher than that of the GF pipe. The $\mathrm{CO}$ conversion rate of the BF pipe during the first 
$100 \mathrm{~s}$ is $24.5 \%$ higher than that of the GF pipe, and the HC conversion rate of the BF pipe is $2.3 \%$ higher than that of the GF pipe. Little difference was observed in diesel particulate matter emissions between the exhaust pipes with the different covering schemes.

Author Contributions: Writing—review and editing, K.Z.; supervision, Y.Z. and L.F.; resources, D.L.; data curation, Y.T. All authors have read and agreed to the published version of the manuscript.

Funding: The authors appreciate the prospective funding support provided by the Nanchang Automotive Innovation Institute and Tongji University (project: Research and Application of Key Thermal Management Technology of Diesel Engine Exhaust System Based on New Basalt Fiber).

Data Availability Statement: The data used to support the findings of this study are included within the article.

Conflicts of Interest: The authors confirm that there are no conflict of interest.

\section{References}

1. Yao, H.; Ni, T.; You, Z. Characterizing pollutant loading from point sources to the Tongqi River of China based on water quality modeling. Int. J. Environ. Sci. Technol. 2019, 16, 6599-6608. [CrossRef]

2. Tangestani, V.; Isfahani, A.H.M. Experimental evaluation of the performance and exhaust emissions of porous medium diesel and Otto engines. Int. J. Environ. Sci. Technol. 2020, 17, 1463-1474. [CrossRef]

3. Resitoglu, I.A.; Altınısık, K.; Keskin, A. The pollutant emissions from diesel engine vehicles and exhaust after treatment systems. Clean Technol. Environ. Policy 2015, 17, 15-27. [CrossRef]

4. Prasad, R.; Bella, V.R. A review on diesel soot emission, its effect and control. Bull. Chem. React. Eng. Catal. 2010, 5, 69-86. [CrossRef]

5. Zhang, Y.H.; Lou, D.M.; Tan, P.Q.; Hu, Z. Experimental study on the particulate matter and nitrogenous compounds from diesel engine retrofitted with DOC+CDPF+SCR. Atmos. Environ. 2018, 177, 45-53. [CrossRef]

6. Resitoglu, I.A.; Keskin, A.; Özarslan, H.; Bulut, H. Selective catalytic reduction of $\mathrm{NO}_{\mathrm{x}}$ emissions by hydrocarbons over Ag-Pt/Al2O3 catalyst in diesel engine. Int. J. Environ. Sci. Technol. 2019, 16, 6959-6966. [CrossRef]

7. Kang, W.; Choi, B.; Jung, S.; Park, S. PM and $\mathrm{NO}_{x}$ reduction characteristics of LNT/DPF + SCR/DPF hybrid system. Energy 2018, 143, 439-447. [CrossRef]

8. Zhang, Y.H.; Lou, D.M.; Tan, P.Q.; Hu, Z. Experimental study on the emission characteristics of a non-road diesel engine equipped with different after-treatment devices. Environ. Sci. Pollut. Res. 2019, 26, 26617-26627. [CrossRef]

9. Yuan, X.M.; Liu, H.Q.; Gao, Y. Diesel Engine SCR Control: Current Development and Future Challenges. Emiss. Control. Sci. Technol. 2015, 1, 121-133. [CrossRef]

10. Koebel, M.; Elsener, M.; Kleemann, M. Urea-SCR: A promising technique to reduce $\mathrm{NO}_{\mathrm{x}}$ emissions from automotive engines. Catal. Today 2000, 59, 335-345. [CrossRef]

11. Sharariar, G.M.H.; Lim, O.T. Investigation of urea aqueous solution injection, droplet breakup and urea decomposition of selective catalytic reduction systems. J. Mech. Sci. Technol. 2018, 32, 3473-3481. [CrossRef]

12. Kogan, F.M.; Nikitina, O.V. Solubility of chrysotile asbestos and basalt fibers in relation to their fibrogenic and carcinogenic action. Environ. Health Perspect. 1994, 102, 205-206.

13. Mcconnell, E.E.; Kamstrup, O.; Musselman, R.; Hesterberg, T.W.; Hesterberg, T.W.; Chevalier, J.; Miiller, W.C.; Thevenaz, P. Chronic inhalation study of size-separated rock and slag wool insulation fibers in Fischer 344/N rats. Inhal. Toxicol. 1994, 6, 571-614. [CrossRef]

14. Chen, J.; Gu, T.Z.; Yang, Z.J.; Min, L.I.; Wang, S.K.; Zhang, Z.G. Effects of Elevated Temperature Treatment on Compositions and Tensile Properties of Several Kinds of Basalt Fibers. J. Mater. Eng. 2017, 45, 61-66.

15. Fiore, V.; Scalici, T.; Di, B.G.; Valenza, A. A review on basalt fibre and its composites. Compos. Part B 2015, 74, 74-94. [CrossRef]

16. Yan, L.; Chu, F.L.; Tuo, W.Y.; Zhao, X.; Wang, Y.; Zhang, P.; Gao, Y. Review of research on basalt fibers and basalt fiber-reinforced composites in China (I): Physicochemical and mechanical properties. Polym. Polym. Compos. 2020. [CrossRef]

17. Militky, J.; Kovaeie, V.; Rubnerova, J. Properties and applications of basalt fibres. Text. Asia 2001, 32, $29-33$.

18. Wolter, N.; Beber, V.C.; Haubold, T.; Sandinge, A.; Blomqvist, P.; Goethals, F.; Van Hove, M.; Jubete, E.; Mayer, B.; Koschek, K. Effects of flame-retardant additives on the manufacturing, mechanical, and fire properties of basalt fiber-reinforced polybenzoxazine. Polym. Eng. Sci. 2021, 61, 551-561. [CrossRef]

19. Bayraktar, O.Y.; Kaplan, G.; Gencel, O.; Benli, A.; Sutcu, M. Physico-mechanical, durability and thermal properties of basalt fiber reinforced foamed concrete containing waste marble powder and slag. Constr. Build. Mater. 2021, 288, 123128. [CrossRef]

20. Bulent, O.; Fazll, A.; Sultan, O. Hot wear properties of ceramic and basalt fiber reinforced hybrid friction materials. Tribol. Int. 2007, 40, 37-48.

21. Novitskii, A.G.; Sudakov, V.V. An unwoven basalt-fiber material for the encasing of fibrous insulation: An alternative to glass cloth. Refract. Ind. Ceram. 2004, 45, 239-241. [CrossRef] 
22. Novitskii, A.G. High-temperature heat-insulating materials based on fibers from basalt-type rock materials. Refract. Ind. Ceram. 2003, 45, 47-50. [CrossRef]

23. Bhat, T.; Chevali, V.; Liu, X.; Feih, S.; Mouritz, A.P. Fire structural resistance of basalt fiber composite. Compos. Part A 2015, 71, 107-115. [CrossRef]

24. Hao, L.C.; Yu, W.D. Comparison of the morphological structure and thermal properties of basalt fiber and glass fiber. J. Xi'an Polytech. Univ. 2009, 23, 327-332.

25. Hafsa, J.; Rajesh, M. A green material from rock: Basalt fiber-A review. J. Text. Inst. 2016, 107, $923-937$.

26. Morozov, M.N.; Bakunov, V.S.; Morozov, E.N.; Aslanova, L.G.; Granovskii, P.A.; Prokshin, V.V.; Zemlyanitsyn, A.A. Materials Based on Basalts from the European North of Russia. Glass Ceram. 2001, 58, 100-104. [CrossRef]

27. Yang, W.J.; Ren, J.N.; Zhang, H.W.; Li, J.; Wu, C.; Gates, I.D.; Gao, Z. Single-atom iron as a promising low-temperature catalyst for selective catalytic reduction of $\mathrm{NO}_{x}$ with $\mathrm{NH}_{3}$ : A theoretical prediction. Fuel 2021, 302, 121041. [CrossRef]

28. Bai, S.Z.; Han, J.L.; Liu, M.; Qin, S.; Wang, G.; Li, G.X. Experimental investigation of exhaust thermal management on $\mathrm{NO}_{\mathrm{x}}$ emissions of heavy-duty diesel engine under the world Harmonized transient cycle (WHTC). Appl. Therm. Eng. 2018, 142, 421-432. [CrossRef]

29. Shen, Y.G.; Liao, P.H.; Chen, C.L.; Peng, Y.Y.; Xiang, Y.H.; Chen, G.S. Experimental Study on Performance Evaluation of a Diesel Engine Equipped with Diesel Oxidation Catalytic and Catalytic Diesel Particulate Filter System. Intern. Combust. Engine Eng. 2020, 41, 17-26.

30. Assanis, D.N.; Wiese, K.; Schwarz, E.; Bryzik, W. The Effects of Ceramic Coatings on Diesel Engine Performance and Exhaust Emissions. SAE Int. J. Engines 1991, 100, 657-665.

31. Meng, Z.W.; Zhang, C.; Li, L.; Zhang, W.; Chen, C. Experimental Study on the Influence of DOC on Diesel Engine Particulate Matter Emission. Intern. Combust. Engine Eng. 2017, 2, 67-72. 